\title{
Dithieno[3,2-b:2', 3'-d]silole-based low band gap polymers: the effect of fluorine and side chain substituents on photovoltaic performance $\uparrow$
}

\author{
Chuantao Gu, a,c Qianqian Zhu, ${ }^{\mathrm{b}}$ Xichang Bao, ${ }^{a}$ Shuguang Wen, ${ }^{a}$ Meng Qiu, ${ }^{a}$ \\ Liangliang Han, ${ }^{a}$ Wei Huang, ${ }^{a}$ Dangqiang Zhu ${ }^{a, c}$ and Renqiang Yang ${ }^{* a, d}$
}

Received 4th June 2015, Accepted 13th July 2015

DOI: $10.1039 /$ c5py00849b www.rsc.org/polymers
Three alkyl-thiophene $\pi$-bridged polymers, PDTS- $h$ DTFBT (P- $h$ F), PDTS-hDTDFBT (P-hDF) and PDTSehDTDFBT (P-ehDF), with different number of $\mathrm{F}$ atoms and side chain substituents are synthesized through a palladium catalyzed Stille coupling reaction. P-hF, P-hDF and P-ehDF show a narrow band gap of $1.56,1.56$ and $1.60 \mathrm{eV}$ with deep lying highest-occupied molecular orbital (HOMO) energy levels of $-5.17,-5.21$ and $-5.35 \mathrm{eV}$, respectively. The optimized P- $h$ DF-based photovoltaic device exhibits an open circuit voltage of $0.593 \mathrm{~V}$, a short-circuit current density of $15.98 \mathrm{~mA} \mathrm{~cm}{ }^{-2}$, a fill factor of $64.8 \%$ and a high energy conversion efficiency of $6.14 \%$, which is partially ascribed to the deep HOMO energy level and good coplanarity. The performance is among the highest reported ones in devices based on polymers with dithieno[3,2-b:2', $\left.3^{\prime}-d\right]$ silole (DTS) as the electron-rich unit and 2,1,3-benzothiadiazole (BT) derivatives as the electron-deficient unit.

\section{Introduction}

Harvesting energy directly from sunlight using photovoltaic technology is considered as one of the most important ways to address growing global energy needs using a renewable resource. ${ }^{1}$ Polymer solar cells (PSCs) have attracted considerable interest from both the academic and industrial communities over the past decade due to advantages such as easy processability over a large-area size via printing or roll-to-roll technologies, low-cost manufacturing, and compatibility with flexible substrates. ${ }^{1-7}$ Three key parameters that determine the power conversion efficiency (PCE) of a solar cell are opencircuit voltage $\left(V_{\mathrm{OC}}\right)$, short-circuit current density $\left(J_{\mathrm{SC}}\right)$ and fill factor (FF). PCE is equal to the product of these three parameters divided by the input power. ${ }^{2,8,9}$ Despite the many advantages of PSCs, a low PCE is still a major impediment to real commercialization. ${ }^{10,11}$ Although remarkable progress has

\footnotetext{
${ }^{a}$ CAS Key Laboratory of Bio-based Materials, Qingdao Institute of Bioenergy and Bioprocess Technology, Chinese Academy of Sciences, Qingdao 266101, China. E-mail: yangrq@qibebt.ac.cn; Fax: +86-532-80662778; Tel: +86-532-80662700 ${ }^{b}$ College of Materials Science and Engineering, Qingdao University of Science and Technology, Qingdao 266042, China

${ }^{c}$ University of Chinese Academy of Sciences, Beijing 100049, China

${ }^{d}$ State Key Laboratory of Luminescent Materials and Devices, South China University of Technology, Guangzhou 510641, China

$\dagger$ Electronic supplementary information (ESI) available: X-ray diffraction, TGA and DSC thermograms, computational study, detailed device parameters of PSCs, and hole mobility. See DOI: 10.1039/c5py00849b
}

been achieved by optimization of the device architectures and developing ideal photovoltaic polymers over the past decade, which led to a higher than $10 \%$ PCE, ${ }^{12-14}$ further improvements are needed for mass production and practical applications. The most successful strategy to improve the PCE is to develop new low band gap donor materials ${ }^{15,16}$ to enlarge overlap with the solar spectrum in the infrared region and ensure efficient harvesting of solar photons, which could improve $J_{\mathrm{SC}}$.

A variety of low band gap conjugated polymers have been designed and synthesized by scientists during the past few decades. One representative polymer is poly[4,4-bis(2-ethylhexyl)-4H-cyclopenta[2,1-b:3,4- $\left.b^{\prime}\right]$ dithiophene-2,6-diyl-alt-2,1,3benzothiadiazole-4,7-diyl] (PCPDTBT). The PSCs based on PCPDTBT:[6,6]-phenyl-C71-butyric acid methyl ester $\left(\mathrm{PC}_{71} \mathrm{BM}\right)$ showed a moderate PCE of $5.5 \%,{ }^{17}$ which is mainly limited by the low $\mathrm{FF}$ and $V_{\mathrm{OC}}$. There are two main strategies to improve the photovoltaic performance of PCРDTBT. The first one is the introduction of strong electron-withdrawing fluorine atom(s) to the electron-deficient unit of the polymer. F-containing PCPDTBTs (PCPDTFBT and PCPDTDFBT) have been reported by several groups. ${ }^{18-22}$ Their encouraging results showed that the highest-occupied molecular orbital (HOMO) energy levels could be lowered by introducing fluorine atom(s) to the electron-deficient unit, as a result, $V_{\mathrm{OC}}$ was increased. However, the solubility has been reduced ${ }^{18,20,21}$ due to the enhanced $\mathrm{F}-\mathrm{H}, \mathrm{F}-\mathrm{F}$ interactions and strong stacking ${ }^{23}$ of polymers; especially for the PCPDTDFBT, the PCE decreased to $3.37 \% .{ }^{21}$ 


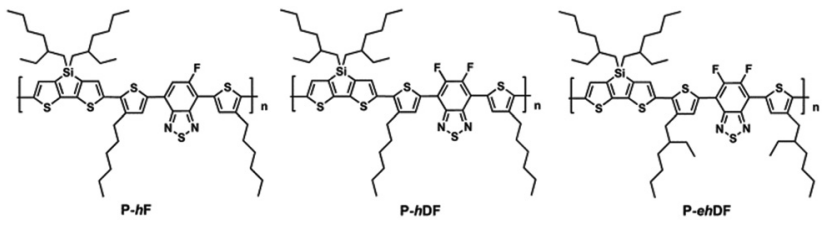

Fig. 1 Chemical structures of P-hF, P-hDF and P-ehDF.

4-Hexylthiophene had been introduced to PCPDTDFBT as a $\pi$-bridge to improve the solubility in our previous work, and the PCE increased from $3.37 \%$ to $5.85 \%{ }^{24}$ The other method is the replacement of the carbon atom at the 4-position of cyclopenta[2,1- $\left.b: 3,4-b^{\prime}\right]$ dithiophene by a silicon atom. The properties of Si-PCPDTBT, named poly[(4,4'-bis(2-ethylhexyl)dithieno[3,2-b:2',3'-d] silole)-2,6-diyl-alt-2,1,3-benzothiadiazole4,7-diyl] (PDTSBT), have been studied by several groups, ${ }^{25-28}$ their results showed that the silicon atom fusion enhances solid-state ordering compared to the carbon-fused analogue, resulting in improved charge transport, which is favorable to obtain a higher $J_{\mathrm{SC}}$ value. ${ }^{29}$ Y. Yang indicated that the long $\mathrm{Si}-$ $\mathrm{C}$ bonds displaced the solubilizing side chains further from the thiophene rings, allowing a stronger $\pi$-stacking interaction to occur, which was the possible reason for the improved charge transport. ${ }^{28}$ However, the solubility of the strong stacking Si-bridged polymers decreased in common organic solvents. $^{27}$

In this work, in order to obtain a deeper HOMO and a higher $J_{\mathrm{SC}}$, the two strategies were combined, an $\mathrm{F}$ atom was introduced to the electron-deficient unit and the carbon bridge was substituted by a silicon atom simultaneously. 4-Hexylthiophene is employed as a $\pi$-bridge to improve the solubility similar to our previous work. ${ }^{24}$ The structures of the resulting polymers, PDTS- $h$ DTFBT (here referred to as $\mathbf{P}-\boldsymbol{h} \mathbf{F}$ ) and PDTS- $h$ DTDFBT (here referred to as P-hDF), are shown in Fig. 1. Previous studies have demonstrated that conformational twisting of the main chain of a polymer is an effective method to lower the HOMO energy level. ${ }^{30-32}$ Thus, to further improve the $V_{\mathrm{OC}}$, the steric group 2-ethylhexyl was introduced to the thiophene $\pi$-bridge, the third polymer was named PDTSehDTDFBT (here referred to as P-ehDF). The thermal stability, and photophysical, electrochemical and photovoltaic properties of the polymers were carefully investigated. The P-hDF/ $\mathrm{PC}_{71} \mathrm{BM}$ based PSC gave a promising PCE of $6.14 \%$ with a $J_{\mathrm{SC}}$ of $15.98 \mathrm{~mA} \mathrm{~cm}^{-2}$, a $V_{\mathrm{OC}}$ of $0.593 \mathrm{~V}$ and an $\mathrm{FF}$ of $64.8 \%$. The P-ehDF/PC ${ }_{71} \mathrm{BM}$ based PSC showed a higher $V_{\mathrm{OC}}$ of $0.805 \mathrm{~V}$ as expected.

\section{Results and discussion}

\section{Synthesis and characterization}

Three polymers were synthesized in good yield (76-83\%) by Stille coupling polymerization, using a $\operatorname{Pd}_{2}(\mathrm{dba})_{3} / \mathrm{P}(o \text {-tol })_{3}$ catalytic system. The polymers were purified by Soxhlet extraction with methanol, hexane, and $\mathrm{CHCl}_{3}$ in succession. $\mathrm{CHCl}_{3}$ fractions were collected, concentrated, reprecipitated in methanol, and dried under vacuum overnight to offer the target polymers. All polymers show excellent solubility in common organic solvents, such as chloroform, chlorobenzene (CB), and dichlorobenzene (DCB). The polymers can even partially dissolve in dichloromethane. The good solubility could be attributed to the alkylthiophene $\pi$-bridge. The molecular weight and polydispersity index (PDI) were determined by gel permeation chromatography (GPC) with calibration against polystyrene standards and tetrahydrofuran (THF) as the eluent. The number average molecular weights $\left(M_{\mathrm{n}}\right)$ of $\mathbf{P}-\boldsymbol{h} \mathbf{F}, \mathbf{P}-\boldsymbol{h} \mathbf{D F}$ and P-ehDF were found to be $15.4,16.2$ and $12.8 \mathrm{~kg} \mathrm{~mol}^{-1}$, with PDIs of $1.86,1.74$ and 2.19, respectively. The crystallinity of the polymer films was investigated using X-ray diffraction (XRD) spectra (Fig. S1†). There are no peaks observed for the polymers, indicating their amorphous nature. ${ }^{33}$ The thermal stability of the polymers was explored by thermogravimetric analysis (TGA) and differential scanning calorimetry (DSC), as shown in Fig. S2. $\dagger$ The three polymers have good thermal stability with onset decomposition temperatures $\left(T_{\mathrm{d}}\right)$ corresponding to a $5 \%$ weight loss at $431{ }^{\circ} \mathrm{C}, 424{ }^{\circ} \mathrm{C}$ and $432{ }^{\circ} \mathrm{C}$, respectively. DSC plots reveal that there is no obvious glass transition for the polymers before $420{ }^{\circ} \mathrm{C}$. Obviously, the thermal stability of the polymers is adequate for their applications in PSCs devices.

\section{Computational study}

The conformational analysis as well as calculations of energies and distributions of the frontier molecular orbitals of these polymers were performed by density functional theory (DFT) using the Gaussian 09 program at the B3LYP/6-31G(d,p) level in the gas phase. ${ }^{34}$ The optimized molecular geometries were confirmed to be minimum-energy conformations since there were no imaginary frequencies by vibrational calculation at the same level. In this work, one repeat unit was chosen, and alkyl chains were simplified to reduce the calculation time (2-ethylhexyl on dithieno[3,2-b:2', $\left.3^{\prime}-d\right]$ silole (DTS) was simplified into methyl, hexyl on the thiophene $\pi$-bridge of $\mathbf{P}-\boldsymbol{h} \mathbf{F}$ and $\mathbf{P}-\boldsymbol{h} \mathbf{D F}$ was simplified into propyl, and 2-ethylhexyl on the thiophene $\pi$-bridge of P-ehDF was simplified into isobutyl). The energies and distributions of the frontier molecular orbitals of the polymers are shown in Fig. S3. $\dagger$ Fig. 2 presents the energy minimized conformational structures. The fluorine substituent has a great influence on inter- or intramolecular interactions. ${ }^{35}$ The noncovalent attractive interaction was demonstrated to be

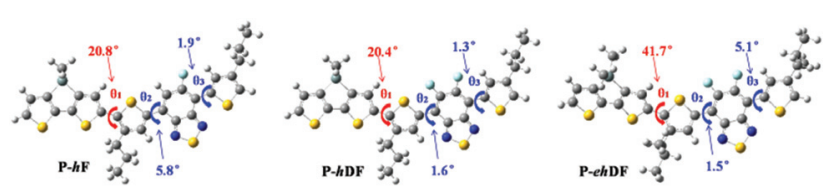

Fig. 2 Minimum energy conformations of the polymers. Color code: gray $(\mathrm{C})$, white $(\mathrm{H})$, blue $(\mathrm{N})$, yellow $(\mathrm{S})$, cyan $(\mathrm{Si})$ and light blue $(\mathrm{F})$. 
effective for minimizing the torsional angles within the polymer backbones. ${ }^{23,35}$ Compared with $\mathbf{P}-\boldsymbol{h} \mathbf{F}$, the introduction of the second $\mathbf{F}$ atom in P-hDF lowers the HOMO energy level $(-4.889 \mathrm{eV})$ and decreases the dihedral angle between 2,1,3benzothiadiazole (BT) and thiophene $\left(\theta_{2}, \theta_{3}\right)$ due to the enhanced $\mathrm{F}-\mathrm{H}, \mathrm{F}-\mathrm{F}$ interactions and strong stacking. ${ }^{23,35}$ The second $\mathrm{F}$ atom has little effect on the dihedral angle between dithieno[3,2- $\left.b: 2^{\prime}, 3^{\prime}-d\right]$ silole (DTS) and thiophene $\left(\theta_{1}\right)$. In other words, the coplanarity of $\mathbf{P}-\boldsymbol{h} \mathbf{D F}$ was better than that of $\mathbf{P}-\boldsymbol{h} \mathbf{F}$, and a higher $J_{\mathrm{SC}}$ of the P-hDF-based device could be expected. ${ }^{1,35-39}$ The introduction of 2-ethylhexyl in P-ehDF further lowers the HOMO energy level to $-4.985 \mathrm{eV}$ and increases the dihedral angle $\theta_{1}$ to $41.7^{\circ}$ due to the large steric hindrance. Therefore, a higher $V_{\mathrm{OC}}$ of P-ehDF-based device can be expected.

\section{Optical properties}

The ultraviolet-visible (UV-vis) absorption spectra of the polymers in dilute chloroform solution and thin films spin-coated on a glass substrate are shown in Fig. 3. The detailed absorption data are summarized in Table 1 . These polymers show similar absorption bands in solution with major absorption peaks at 596, 582 and 569 nm for P-hF, P-hDF and P-ehDF, respectively. This characteristic peak can be attributed to the intramolecular charge transfer (ICT) between donor units and acceptor units. ${ }^{18}$ The other absorption band near $430 \mathrm{~nm}$ was due to the $\pi-\pi^{*}$ transition. $^{40}$ In the solid state, the main absorption peaks become broader and red shift toward a longer wavelength with maximum absorption peaks at 655, 645 and $621 \mathrm{~nm}$ for P-hF, P-hDF and P-ehDF, respectively. This behavior is ascribed to the enhanced intermolecular inter-

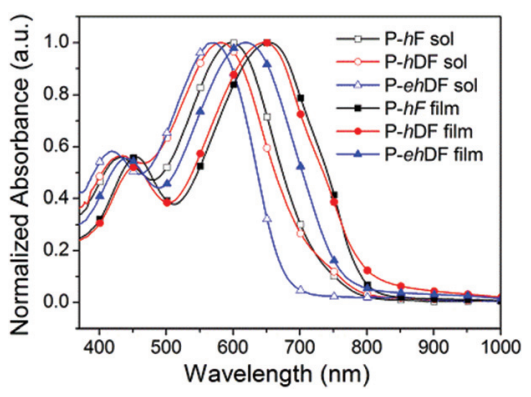

Fig. 3 UV-vis absorption spectra of P-hF, P-hDF and P-ehDF in chloroform solutions and as thin films. actions between the polymer main chains and the planarization effect of the $\pi$-conjugated polymer backbone. ${ }^{24}$ The more red shifts from solution to solid film means a better coplanar structure and stronger interchain $\pi-\pi$ stacking in the solid state, ${ }^{28,41}$ which is favorable to obtain a higher $J_{\mathrm{SC}}{ }^{35-39}$ The red shifts of P- $\boldsymbol{h} \mathbf{F}, \mathbf{P}-\boldsymbol{h} \mathbf{D F}$ and P-ehDF were 59, 63 and $52 \mathrm{~nm}$, respectively. It means that $\mathbf{P}-\boldsymbol{h} \mathbf{F}$ and $\mathbf{P}-\boldsymbol{h} \mathbf{D F}$ showed a bigger red shift than that of P-ehDF, which may be ascribed to the larger steric hindrance of a 2-ethylhexyl side chain on the $\pi$-bridge of P-ehDF thus distorting the backbone (Fig. 2). The optical band gap $\left(E_{\mathrm{g}}^{\mathrm{opt}}\right)$ of $\mathbf{P}-\boldsymbol{h} \mathbf{F}, \mathbf{P}-\boldsymbol{h D F}$ and P-ehDF can be calculated to be 1.56, 1.56 and $1.63 \mathrm{eV}$, respectively, from their onset absorption as thin films. It has been proven that attaching a fluorine atom to the electron deficient subunits of low band gap polymers could simultaneously lower the HOMO and lowest unoccupied molecular orbital (LUMO) level energies, while having no or only a minor effect on the $E_{\mathrm{g}}^{\mathrm{opt}} \cdot{ }^{20,42,43}$ The same $E_{\mathrm{g}}^{\mathrm{opt}}$ of $\mathbf{P}-\boldsymbol{h} \mathbf{F}$ and $\mathbf{P}-\boldsymbol{h} \mathbf{D F}$ is in agreement with previously reported results. The larger $E_{\mathrm{g}}^{\text {opt }}$ of P-ehDF may be ascribed to the tortuous polymer backbone which was caused by the stronger steric hindrance ${ }^{31,32}$ of the 2-ethylhexyl side chain on the $\pi$-bridge.

\section{Electrochemical properties}

Cyclic voltammetry (CV) measurement was performed to investigate the electrochemical properties of the polymers. The saturated calomel reference electrode (SCE) was calibrated against the $\mathrm{Fc} / \mathrm{Fc}^{+}$system to be $4.41 \mathrm{eV}$ in this work. As shown in Fig. 4a, all polymers show reversible oxidation behaviors. The onsets of oxidation potentials ( $E_{\mathrm{on}}^{\mathrm{ox}}$ ) of P-hF, P-hDF and P-ehDF were observed at $0.76,0.80$ and $0.94 \mathrm{~V}$ vs. SCE, corresponding to the HOMO levels at $-5.17,-5.21$ and $-5.35 \mathrm{eV}$, respectively. The onsets of reduction potentials $\left(E_{\mathrm{on}}^{\mathrm{red}}\right)$ of $\mathbf{P}-\boldsymbol{h} \mathbf{F}, \mathbf{P}-\boldsymbol{h} \mathbf{D F}$ and P-ehDF were observed at $-0.70,-0.67$ and $-0.60 \mathrm{~V} v \boldsymbol{s}$. SCE, corresponding to the LUMO levels at $-3.71,-3.74$ and $-3.80 \mathrm{eV}$, respectively. Relevant data are summarized in Table 1. The HOMO of $\mathbf{P}-\boldsymbol{h} \mathbf{D F}$ is slightly lower than that of $\mathbf{P}-\boldsymbol{h} \mathbf{F}$, which is caused by the second electron-withdrawing F atom. Interestingly, P-ehDF exhibited a more deeper HOMO of $-5.35 \mathrm{eV}$, which can be ascribed to the synergistic effect of the two $\mathrm{F}$ atoms and the distorted polymer backbone caused by the steric hindrance effect of the 2-ethylhexyl side chain on the $\pi$-bridge, ${ }^{31,32}$ and the result was consistent with the calculations. Therefore, a higher $V_{\mathrm{OC}}$ in P-ehDF-based PSCs can be expected, since $V_{\mathrm{OC}}$ is proportional to the offset between the

Table 1 Optical, electrochemical and thermal properties of P- $h$ F, P-hDF and P-ehDF

\begin{tabular}{|c|c|c|c|c|c|c|c|c|}
\hline \multirow[b]{2}{*}{ Polymer } & \multicolumn{2}{|l|}{ Solution $^{a}$} & \multicolumn{3}{|l|}{ Thin film } & \multirow[b]{2}{*}{$E_{\mathrm{on}}^{\mathrm{ox}} / \mathrm{HOMO}^{c}(\mathrm{~V} / \mathrm{eV})$} & \multirow[b]{2}{*}{$E_{\mathrm{on}}^{\mathrm{red}} / \mathrm{LUMO}^{d}(\mathrm{~V} / \mathrm{eV})$} & \multirow[b]{2}{*}{$T_{\mathrm{d}}\left({ }^{\circ} \mathrm{C}\right)$} \\
\hline & $\lambda_{\max }(\mathrm{nm})$ & $\lambda_{\text {onset }}(\mathrm{nm})$ & $\lambda_{\max }(\mathrm{nm})$ & $\lambda_{\text {onset }}(\mathrm{nm})$ & $E_{\mathrm{g}}^{\mathrm{opt} b}(\mathrm{eV})$ & & & \\
\hline $\mathrm{P}-h \mathrm{~F}$ & 596 & 733 & 655 & 796 & 1.56 & $0.76 /-5.17$ & $-0.70 /-3.71$ & 431 \\
\hline P-hDF & 582 & 718 & 645 & 796 & 1.56 & $0.80 /-5.21$ & $-0.67 /-3.74$ & 424 \\
\hline P-ehDF & 569 & 676 & 621 & 760 & 1.63 & $0.94 /-5.35$ & $-0.61 /-3.80$ & 432 \\
\hline
\end{tabular}

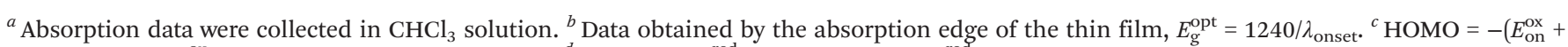
$4.41) \mathrm{eV}$, where $E_{\mathrm{on}}^{\mathrm{ox}}$ is the onset oxidation potential. ${ }^{d} \mathrm{LUMO}=-\left(E_{\mathrm{on}}^{\mathrm{red}}+4.41\right) \mathrm{eV}$, where $E_{\mathrm{on}}^{\text {red }}$ is the onset reduction potential. 

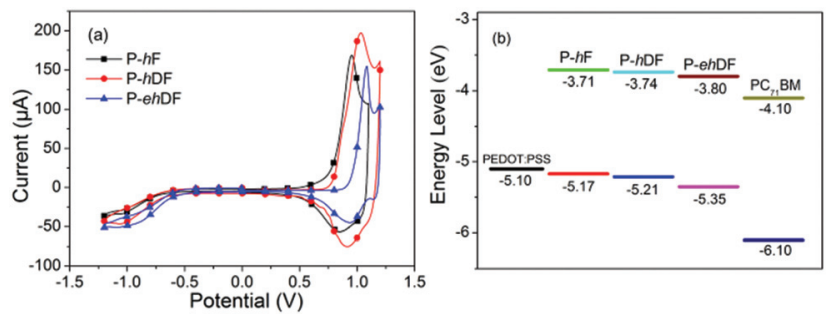

Fig. 4 Cyclic voltammograms (a) and the energy level diagram (b) of P-hF, P-hDF and P-ehDF.

HOMO of the polymeric donor and the LUMO of the fullerene acceptor. ${ }^{43}$ In order to make a clear comparison, the electronic energy level diagram of these polymers and $\mathrm{PC}_{71} \mathrm{BM}$ is shown in Fig. 4b. The LUMO differences between the polymers and $\mathrm{PC}_{71} \mathrm{BM}$ are $0.39,0.36$ and $0.30 \mathrm{eV}$, respectively, and they are large enough to overcome the exciton binding energy and thus guarantee efficient exciton dissociation and transfer. ${ }^{38,43,44}$

\section{Photovoltaic performance}

In order to examine the photovoltaic properties of these polymers, the bulk heterojunction PSCs were fabricated with a device structure of ITO/PEDOT:PSS/polmer: $\mathrm{PC}_{71} \mathrm{BM} / \mathrm{Ca} / \mathrm{Al}$, and tested under a simulated AM 1.5G illumination of $100 \mathrm{~mW}$ $\mathrm{cm}^{-2}$. Several batch devices were prepared to optimize the processing conditions such as the polymer to $\mathrm{PC}_{71} \mathrm{BM}$ weight ratio and the additive 1,8-diiodooctane (DIO) concentration. The current density $v s$. voltage $(J-V)$ curves are shown in Fig. 5, and the detailed device parameters are summarized in Tables 2 and S1.† One can observe that the $V_{\mathrm{OC}}$ of P-hDF is higher than that of $\mathbf{P}-\boldsymbol{h} \mathbf{F}$, which could be ascribed to the low lying HOMO of P-hDF caused by the second F atom. Surprisingly, the $V_{\mathrm{OC}}$ of $\mathbf{P}-\boldsymbol{e h D F}$ is more than $0.1 \mathrm{~V}$ and higher than that of P- $h \mathbf{D F}$, resulting from the lower lying HOMO of P-ehDF due to the two $\mathrm{F}$ atoms and twisted polymer backbone caused by the larger steric hindrance $e^{30,31}$ of the 2-ethylhexyl side chain on the $\pi$-bridge. The result is in accordance with the energy level obtained from $\mathrm{CV}$ and calculations. The $V_{\mathrm{OC}}$ of all polymers were decreased after the addition of DIO, which is consistent

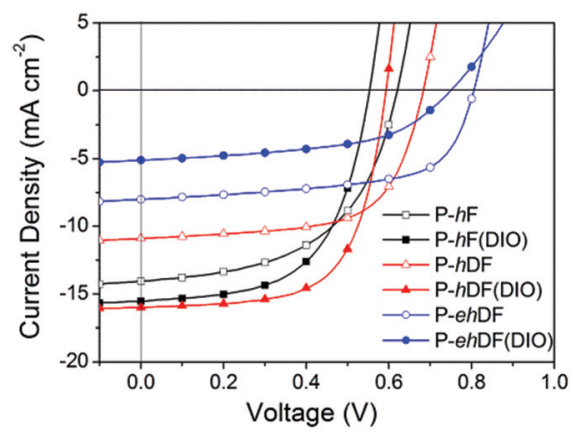

Fig. $5 \mathrm{~J}-V$ curves of polymer/PC $\mathrm{P}_{71} \mathrm{BM}$-based regular single solar cells under $\mathrm{AM} 1.5 \mathrm{G}$ illumination, $100 \mathrm{~mW} \mathrm{~cm}^{-2}$.
Table 2 PSCs performance with device configuration ITO/PEDOT/ polymer: $\mathrm{PC}_{71} \mathrm{BM} / \mathrm{Ca} / \mathrm{Al}$

\begin{tabular}{|c|c|c|c|c|c|c|}
\hline Active layer & Ratio & $\begin{array}{l}\text { DIO } \\
(\%)\end{array}$ & $\begin{array}{l}V_{\mathrm{OC}} \\
(\mathrm{V})\end{array}$ & $\begin{array}{l}J_{\mathrm{SC}} \\
\left(\mathrm{mA} \mathrm{cm}{ }^{-2}\right)\end{array}$ & $\begin{array}{l}\mathrm{FF} \\
(\%)\end{array}$ & $\begin{array}{l}\text { PCE } \\
(\%)\end{array}$ \\
\hline $\mathbf{P}-\boldsymbol{h} \mathbf{F}: \mathrm{PC}_{71} \mathrm{BM}$ & $1: 1$ & 0 & 0.620 & 14.04 & 53.5 & 4.66 \\
\hline $\mathbf{P}-\boldsymbol{h} \mathbf{F}: \mathrm{PC}_{71} \mathrm{BM}$ & $1: 1$ & 0.5 & 0.553 & 15.51 & 58.8 & 5.04 \\
\hline P-hDF : $\mathrm{PC}_{71} \mathrm{BM}$ & $1: 1$ & 0 & 0.683 & 10.90 & 64.0 & 4.76 \\
\hline P-hDF : $\mathrm{PC}_{71} \mathrm{BM}$ & $1: 1$ & 1 & 0.593 & 15.98 & 64.8 & 6.14 \\
\hline P-ehDF : $\mathrm{PC}_{71} \mathrm{BM}$ & $1: 2$ & 0 & 0.805 & 8.01 & 62.6 & 4.03 \\
\hline P-ehDF : $\mathrm{PC}_{71} \mathrm{BM}$ & $1: 2$ & 2 & 0.749 & 5.11 & 52.4 & 2.01 \\
\hline
\end{tabular}

with previous reports. ${ }^{20,45,46}$ The addition of DIO to the blend solution is found to increase $J_{\mathrm{SC}}$ and FF in P-hF and P-hDF based devices, however, $J_{\mathrm{SC}}$ and FF decreased in P-ehDF based devices. The $J_{\text {SC }}$ of P-hF and P-hDF based devices was optimized to 15.51 and $15.98 \mathrm{~mA} \mathrm{~cm}^{-2}$, which was higher than that of their carbon-analogues (10.88 and $\left.13.58 \mathrm{~mA} \mathrm{~cm}{ }^{-2}\right) .^{24}$ This could be attributed to the stronger $\pi$-stacking interaction and enhanced solid state ordering compared to the carbonfused analogue. ${ }^{27-29}$ Finally, the highest PCE of $6.14 \%$ for P-hDF is obtained with a $V_{\mathrm{OC}}$ of $0.593 \mathrm{~V}$, a $J_{\mathrm{SC}}$ of $15.98 \mathrm{~mA}$ $\mathrm{cm}^{-2}$, and a $\mathrm{FF}$ of $64.8 \%$, when the device was fabricated at a donor-acceptor weight ratio of $1: 1$ in DCB with a total concentration of $24 \mathrm{mg} \mathrm{mL}^{-1}$ containing $1 \%$ DIO as an additive.

External quantum efficiency (EQE) curves of the devices based on these polymers prepared with the optimal fabrication processes are shown in Fig. 6. It can be seen that the devices exhibit a broad response over the range $320-780 \mathrm{~nm}$. The EQE value between 350 and $700 \mathrm{~nm}$ for the P-hDF device is slightly higher than that of the $\mathbf{P}-\boldsymbol{h} \mathbf{F}$ device. Although the P-ehDF device exhibits a broad response, yet the EQE peak value is only $39 \%$. The integrated $J_{\mathrm{SC}}$ from EQE is $15.19,15.57$ and $7.70 \mathrm{~mA} \mathrm{~cm} \mathbf{~ c m}^{-2}$ for P-hF, P-hDF and P-ehDF based devices, respectively, which are consistent with the measured $J_{\mathrm{SC}}$ values. Mobility measurements via a space charge limited current (SCLC) method ${ }^{42,46,47}$ disclose a hole mobility of $2.02 \times$ $10^{-4} \mathrm{~cm}^{2} \mathrm{~V}^{-1} \mathrm{~s}^{-1}$ for the P-hF : $\mathrm{PC}_{71} \mathrm{BM}$ device and $2.53 \times 10^{-4}$ $\mathrm{cm}^{2} \mathrm{~V}^{-1} \mathrm{~s}^{-1}$ for the P-hDF : $\mathrm{PC}_{71} \mathrm{BM}$ device (Fig. S4 $\dagger$ ), both three orders of magnitude higher than that of the P-ehDF : $\mathrm{PC}_{71} \mathrm{BM}$ device $\left(4.77 \times 10^{-7} \mathrm{~cm}^{2} \mathrm{~V}^{-1} \mathrm{~s}^{-1}\right)$. The low hole mobility

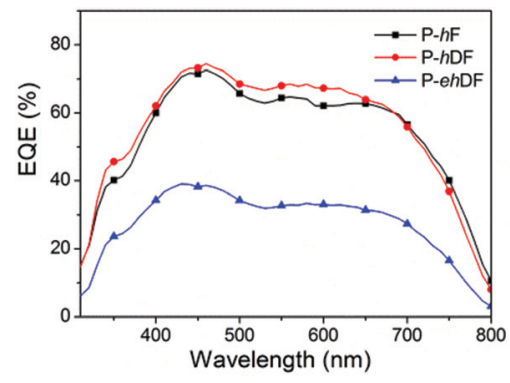

Fig. 6 EQE curves for blends of P-hF, P- $h$ DF and P-ehDF with $\mathrm{PC}_{71} \mathrm{BM}$ processed from DCB solutions. 
may be caused by the increased dihedral angle between the donor unit and the flanking thiophene rings (Fig. 2), which decrease the coplanarity of the backbone. ${ }^{35,46}$ The quite low hole mobility could be due to an intrinsic reason that the P-ehDF : $\mathrm{PC}_{71} \mathrm{BM}$ device exhibits lower $J_{\mathrm{SC}} \cdot{ }^{36}$

\section{Morphology study}

To deeply understand the different photovoltaic properties, atom force microscopy (AFM) images of the active layer surface for the best performance device without or with DIO were collected. Fig. 7 shows the height images of P-hF : $\mathrm{PC}_{71} \mathrm{BM}(1: 1)$, P-hDF : $\mathrm{PC}_{71} \mathrm{BM}(1: 1)$ and P-ehDF : $\mathrm{PC}_{71} \mathrm{BM}(1: 2)$ blend films processed without or with the DIO additive, and the corresponding phase images are shown in Fig. 8. The surface of the $\mathbf{P}-\boldsymbol{h} \mathbf{F}: \mathrm{PC}_{71} \mathrm{BM}$ film without DIO was packed with small holes with a root-mean-square (RMS) surface roughness of $0.80 \mathrm{~nm}$ (Fig. 7a). When processed with $0.5 \%$ DIO (Fig. 7d), the film formed a pin-hole free and a little rough surface topography $(\mathrm{RMS}=1.59 \mathrm{~nm})$. The surfaces of the P-hDF : $\mathrm{PC}_{71} \mathrm{BM}$ film without (Fig. 7b) or with (Fig. 7e) DIO were both uniform without holes. The RMS was increased from $1.57 \mathrm{~nm}$ to $5.41 \mathrm{~nm}$ after addition of $1 \%$ DIO, indicating appropriately

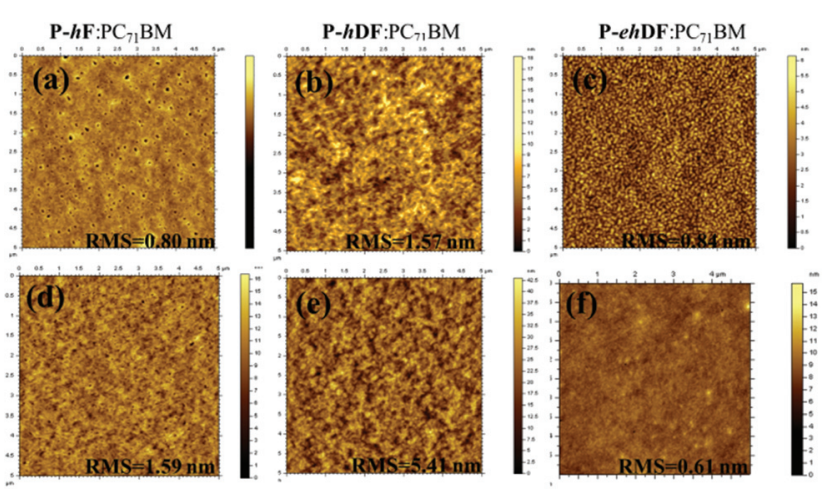

Fig. 7 AFM height images of the active layer containing $P-h F: P C_{71} B M$ $(a, d), P-h D F: P C_{71} B M(b, e)$ and P-ehDF : $P_{71} B M(c, f)$ without (top) or with (bottom) DIO. The scan size is $5 \mu \mathrm{m} \times 5 \mu \mathrm{m}$.
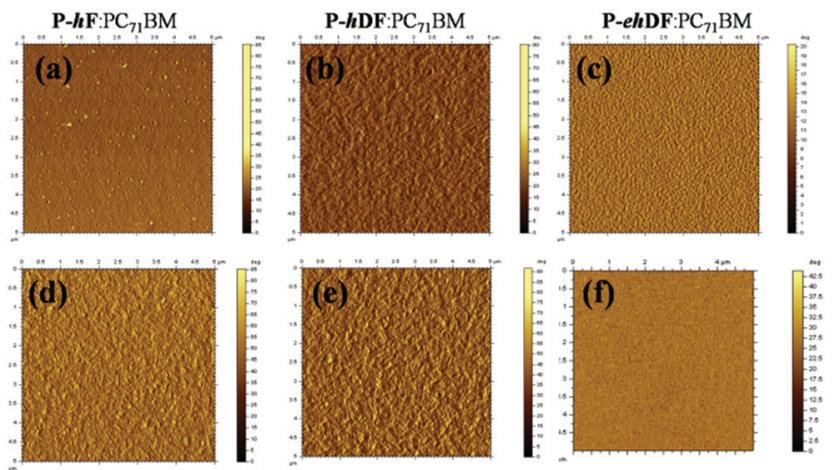

Fig. 8 AFM phase images of the active layer containing $P-h F: P C_{71} B M$ $(a, d), P-h D F: P C_{71} B M(b, e)$ and P-ehDF : $\mathrm{PC}_{71} \mathrm{BM}(c, f)$ without (top) or with (bottom) DIO. The scan size is $5 \mu \mathrm{m} \times 5 \mu \mathrm{m}$. enhanced aggregations (Fig. 8e). ${ }^{48}$ Using DIO can usually facilitate obtaining appropriate phase-separated domains. If the phase-separated domains are preferable without DIO in some systems of polymer/ $\mathrm{PC}_{71} \mathrm{BM}$, the additive of $\mathrm{DIO}$ would not result in higher PCE. ${ }^{8,46,49,50}$ For the P-ehDF : $\mathrm{PC}_{71} \mathrm{BM}$ blending film, the addition of $2 \%$ DIO resulted in quite a smooth surface topography (RMS $=0.61 \mathrm{~nm}$, Fig. 7f) but without effective phase separation (Fig. 8f), which may be a main reason that P-ehDF exhibits a smaller $J_{\mathrm{SC}}$. The AFM results revealed that the addition of the DIO additive enabled the formation of interpenetrating and interconnected phase separation morphology of P-hF : $\mathrm{PC}_{71} \mathrm{BM}$ and P-hDF : $\mathrm{PC}_{71} \mathrm{BM}$, however, just the reverse for the P-ehDF : $\mathrm{PC}_{71} \mathrm{BM}$ case, which were consistent with the photovoltaic performance of these polymers (Table 2). $8,46,49,50$

\section{Conclusions}

Three low band gap polymers based on DTS and BT derivatives with different number of $\mathrm{F}$ atoms and side chains were designed and synthesized. All the polymers, P-hF, P-hDF and P-ehDF, exhibited excellent solubility and good thermal stability until decomposition temperatures around $420{ }^{\circ} \mathrm{C}$. P-hF, P$\boldsymbol{h D F}$ and P-ehDF showed narrow $E_{\mathrm{g}}^{\mathrm{opt}}$ of $1.56,1.56$ and $1.60 \mathrm{eV}$ with deep lying HOMO energy levels of $-5.17,-5.21$ and -5.35 $\mathrm{eV}$, respectively. The photovoltaic properties of the polymers were carefully optimized with different polymer/ $/ \mathrm{PC}_{71} \mathrm{BM}$ weight ratios and additive volume ratios. For the optimized blend of $\mathbf{P}-\boldsymbol{h} \mathbf{F}$, a $V_{\mathrm{OC}}$ of $0.553 \mathrm{~V}$, a $J_{\mathrm{SC}}$ of $15.51 \mathrm{~mA} \mathrm{~cm}^{-2}$ and a $\mathrm{FF}$ of $58.8 \%$ were obtained, resulting in a PCE of $5.04 \%$. Contributed by the slightly deeper HOMO energy level and better coplanarity structure, the optimized P-hDF-based device exhibited higher $V_{\mathrm{OC}}$ of $0.593 \mathrm{~V}, J_{\mathrm{SC}}$ of $15.98 \mathrm{~mA} \mathrm{~cm}^{-2}, \mathrm{FF}$ of $64.8 \%$ and a higher PCE of 6.14\%. The HOMO level of P-ehDF was $0.14 \mathrm{eV}$ lower than that of P-hDF due to the bigger dihedral angle between DTS and thiophene which was caused by the increased steric hindrance of 2-ethylhexyl, resulting in a higher $V_{\mathrm{OC}}$ of $0.805 \mathrm{~V}$. This was one of the highest $V_{\text {OC }}$ values obtained in devices based on polymers with DTS as the electron-rich unit and BT derivatives as the electron-deficient unit. However, the $J_{\mathrm{SC}}$ was decreased to $8.01 \mathrm{~mA} \mathrm{~cm}^{-2}$, which was ascribed to unfavorable surface morphology and low hole mobility caused by the twisted backbone. As a result, the P-ehDF-based device only gave a PCE of $4.03 \%$. Our work shows that the photovoltaic performance of a polymer can be tuned by the electron withdrawing groups and steric hindrance of side chains.

\section{Experimental}

\section{Measurements}

${ }^{1} \mathrm{H}$ NMR spectra were recorded on a Bruker Advance III 600 (600 MHz). UV-vis absorption spectra were recorded at room temperature using a Hitachi U-4100 spectrophotometer. CV measurements were performed on a CHI 660D electrochemical 
workstation equipped with a three-electrode cell consisting of a platinum disk working electrode (2.0 $\mathrm{mm}$ in diameter), a saturated calomel reference electrode (SCE) and a platinum wire counter electrode. The measurements were carried out in anhydrous acetonitrile containing $0.1 \mathrm{~mol} \mathrm{~L}^{-1}$ tetrabutylammonium phosphorus hexafluoride $\left(\mathrm{Bu}_{4} \mathrm{NPF}_{6}\right)$ as the supporting electrolyte under a nitrogen atmosphere at a scan rate of $50 \mathrm{mV} \mathrm{s}^{-1}$. Thin films were deposited from chloroform solution onto the platinum working electrodes and dried under nitrogen prior to measurement. The redox potential of the ferrocene/ferrocenium $\left(\mathrm{Fc} / \mathrm{Fc}^{+}\right)$internal reference is $0.39 \mathrm{~V} v s$. SCE. HOMO and LUMO energy levels were determined by calculating the empirical formula of $\mathrm{HOMO}=-\left(E_{\mathrm{on}}^{\mathrm{ox}}+4.80-\right.$ $\left.E_{1 / 2,\left(\mathrm{Fc} / \mathrm{Fc}^{+}\right)}\right)$, LUMO $=-\left(E_{\mathrm{on}}^{\mathrm{red}}+4.80-E_{1 / 2,\left(\mathrm{Fc} / \mathrm{Fc}^{+}\right)}\right)$, where $E_{\mathrm{on}}^{\mathrm{ox}}$ is the onset oxidation potential and $E_{\mathrm{on}}^{\mathrm{red}}$ is the onset reduction potential. TGA and DSC measurements were performed by an STA-409 at a heating rate of $10{ }^{\circ} \mathrm{C} \mathrm{min}^{-1}$, under the protection of a nitrogen atmosphere. XRD spectra were recorded on a Bruker D8 Advance. GPC analysis was made using THF as the eluent. The surface roughness and morphology of thin films were characterized by AFM on an Agilent 5400.

\section{Fabrication of polymer photovoltaic devices}

Photovoltaic devices were fabricated on $15 \mathrm{~mm} \times 15 \mathrm{~mm}$ patterned indium tin oxide (ITO) coated glass substrates with a layered structure of ITO/PEDOT:PSS (40 nm)/polymer: $\mathrm{PC}_{71} \mathrm{BM}$ blend $(\sim 110 \mathrm{~nm}) / \mathrm{Ca}(10 \mathrm{~nm}) / \mathrm{Al}(100 \mathrm{~nm})$. The ITO coated glass substrates were cleaned in ultrasonic bath in acetone, methanol and isopropyl alcohol sequentially. The substrates were treated with oxygen plasma for $6 \mathrm{~min}$, then spin-coated with PEDOT:PSS at $4000 \mathrm{rpm}$, and annealed in an oven for $20 \mathrm{~min}$ at $160{ }^{\circ} \mathrm{C}$. The polymer and $\mathrm{PC}_{71} \mathrm{BM}$ were dissolved in deoxygenated anhydrous DCB in different weight ratios and the total concentration of the polymer/ $\mathrm{PC}_{71} \mathrm{BM}$ blending solution was $24 \mathrm{mg} \mathrm{mL}^{-1}$. The solutions were stirred overnight in a nitrogen filled glovebox. An active layer consisting of the blend of polymer and $\mathrm{PC}_{71} \mathrm{BM}$ was then spin-coated on PEDOT:PSS. Subsequently $\mathrm{Ca}(10 \mathrm{~nm})$ and $\mathrm{Al}(100 \mathrm{~nm})$ were thermally evaporated under a vacuum of $\sim 2 \times 10^{-4} \mathrm{~Pa}$ on top of the active layer as a cathode. The device area was $0.1 \mathrm{~cm}^{2}$ defined by shadow mask. Photovoltaic performance was characterized under illumination with an AM $1.5 \mathrm{G}\left(100 \mathrm{~mW} \mathrm{~cm}^{-2}\right)$, and $J-V$ curves were recorded by using a Keithley 2420. EQE of solar cells was analyzed by a certified Newport incident photon conversion efficiency (IPCE) measurement system.

\section{Materials}

All reagents and starting materials were purchased from commercial sources and used without further purification unless otherwise mentioned. All air and water sensitive reactions were performed under a nitrogen atmosphere. THF and toluene were distilled from sodium, with benzophenone as an indicator. $\quad 4,4^{\prime}$-Bis(2-ethylhexyl)-5, $5^{\prime}$-bis(trimethylstannanyl)dithieno[3,2-b:2', $3^{\prime}$ - $\left.d\right]$ silole (DTS-Sn), ${ }^{25}$ 4,7-bis(5-bromo-4-hexylthienyl)-5-fluoro-2,1,3-benzothiadiazole ( $h$ DTFBT-Br), ${ }^{24} 4,7$-bis(5-bromo-4-hexylthienyl)-5,6-difluoro-2,1,3-benzothiadiazole
( $h$ DTDFBT-Br $)^{32}$ and 4,7-bis(5-bromo-4-(2-ethylhexyl)-thienyl)5,6-difluoro-2,1,3-benzothiadiazole (ehDTDFBT-Br) ${ }^{32,51}$ were synthesized according to the previously reported methods.

\section{General synthetic procedure of polymers}

The polymers were prepared by the same procedure through the Stille coupling reaction. In a $25 \mathrm{~mL}$ round-bottom flask, DTS-Sn (0.19 mmole), hDTFBT-Br ( $h$ DTDFBT-Br or ehDTDFBT-Br) (0.19 mmole), tris(dibenzylideneacetone)dipalladium $(6 \mathrm{mg})$ and tris $(o$-tolyl)phosphine $(14 \mathrm{mg})$ were subjected to three cycles of evacuation/nitrogen purging and then $5 \mathrm{~mL}$ of anhydrous toluene was added. The oil bath was heated to $110^{\circ} \mathrm{C}$ slowly, and the reactant was stirred for $48 \mathrm{~h}$ at this temperature under a nitrogen atmosphere. The reaction mixture was cooled down to room temperature and precipitated in $150 \mathrm{~mL}$ of methanol. The precipitate was filtered then purified by Soxhlet extraction with methanol, hexane, and $\mathrm{CHCl}_{3}$ in succession. $\mathrm{CHCl}_{3}$ fractions were collected, concentrated, reprecipitated in methanol, and dried under vacuum overnight to give the target polymers.

P-hF: DTS-Sn (144.1 mg, $0.194 \mathrm{mmol})$ and $h$ DTFBT-Br (124.7 $\mathrm{mg}, 0.194 \mathrm{mmol}$ ) were used in this polymerization following the above procedure, and the polymer was obtained as a blue solid (143.4 mg, yield 82.2\%). ${ }^{1} \mathrm{H}$ NMR (600 MHz, $\left.\mathrm{CDCl}_{3}\right): \delta(\mathrm{ppm}) 8.12$ (br, 1H), $7.98(\mathrm{br}, 1 \mathrm{H}), 7.71$ (br, 1H), 7.22 (br, 2H), 2.87 (br, 4H), 1.76 (br, 4H), 1.53-1.16 (br, 34H), 0.98-0.82 (br, 18H). Molecular weight: $M_{\mathrm{n}}=15400 \mathrm{~g} \mathrm{~mol}^{-1}$, $\mathrm{PDI}=1.86$.

P-hDF: DTS-Sn (145.4 mg, $0.195 \mathrm{mmol})$ and $h$ DTDFBT-Br (129.4 $\mathrm{mg}, 0.195 \mathrm{mmol})$ were used, and the polymer was obtained as a dark blue solid (150.0 mg, yield 83.5\%). ${ }^{1} \mathrm{H}$ NMR $\left(600 \mathrm{MHz}, \mathrm{CDCl}_{3}\right): \delta(\mathrm{ppm}) 8.10(\mathrm{br}, 2 \mathrm{H}), 7.20(\mathrm{br}, 2 \mathrm{H}), 2.88$ (br, 4H), 1.76 (br, 4H), 1.50-1.14 (br, 34H), 1.00-0.80 (br, 18H). Molecular weight: $M_{\mathrm{n}}=16200 \mathrm{~g} \mathrm{~mol}^{-1}$, PDI $=1.74$.

P-ehDF: DTS-Sn (142.0 mg, $0.191 \mathrm{mmol}$ ) and ehDTDFBT-Br (137.1 $\mathrm{mg}, 0.191 \mathrm{mmol}$ ) were used, and the polymer was obtained as a dark blue solid (133.1 mg, yield 76.2\%). ${ }^{1} \mathrm{H}$ NMR $\left(600 \mathrm{MHz}, \mathrm{CDCl}_{3}\right): \delta(\mathrm{ppm}) 8.10(\mathrm{br}, 2 \mathrm{H}), 7.20(\mathrm{br}, 2 \mathrm{H}), 2.84$ (br, 4H), 1.80 (br, 2H), 1.51 (br, 2H), 1.41-1.20 (br, 36H), 0.93-0.83 (br, 24H). Molecular weight: $M_{\mathrm{n}}=12800 \mathrm{~g} \mathrm{~mol}^{-1}$, $\mathrm{PDI}=2.19$.

\section{Acknowledgements}

This work was supported by the National Natural Science Foundation of China (21202181, 21274161, 51173199, and 61107090), Ministry of Science and Technology of China (2014CB643501, 2010DFA52310), and the Department of Science and Technology of Shandong Province (ZR2012BQ021).

\section{Notes and references}

1 Y.-J. Cheng, S.-H. Yang and C.-S. Hsu, Chem. Rev., 2009, 109, 5868-5923. 
2 L. Dou, J. You, Z. Hong, Z. Xu, G. Li, R. A. Street and Y. Yang, Adv. Mater., 2013, 25, 6642-6671.

3 L. Ye, S. Zhang, L. Huo, M. Zhang and J. Hou, Acc. Chem. Res., 2014, 47, 1595-1603.

4 Z. He, C. Zhong, X. Huang, W. Y. Wong, H. Wu, L. Chen, S. Su and Y. Cao, Adv. Mater., 2011, 23, 4636-4643.

5 L. Han, W. Chen, T. Hu, J. Ren, M. Qiu, Y. Zhou, D. Zhu, N. Wang, M. Sun and R. Yang, ACS Macro Lett., 2015, 4, 361-366.

6 H. Lv, X. Zhao, Z. Li, D. Yang, Z. Wang and X. Yang, Polym. Chem., 2014, 5, 6279-6286.

7 L. Han, X. Bao, T. Hu, Z. Du, W. Chen, D. Zhu, Q. Liu, M. Sun and R. Yang, Macromol. Rapid Commun., 2014, 35, 1153-1157.

8 H.-C. Liao, C.-C. Ho, C.-Y. Chang, M.-H. Jao, S. B. Darling and W.-F. Su, Mater. Today, 2013, 16, 326-336.

9 J. Wang, M. Xiao, W. Chen, M. Qiu, Z. Du, W. Zhu, S. Wen, N. Wang and R. Yang, Macromolecules, 2014, 47, 78237830.

10 C. M. Amb, S. Chen, K. R. Graham, J. Subbiah, C. E. Small, F. So and J. R. Reynolds, J. Am. Chem. Soc., 2011, 133, 10062-10065.

11 G. Li, R. Zhu and Y. Yang, Nat. Photonics, 2012, 6, 153-161.

12 J. You, L. Dou, K. Yoshimura, T. Kato, K. Ohya, T. Moriarty, K. Emery, C. C. Chen, J. Gao, G. Li and Y. Yang, Nat. Commun., 2013, 4, 1446.

13 C. C. Chen, W. H. Chang, K. Yoshimura, K. Ohya, J. You, J. Gao, Z. Hong and Y. Yang, Adv. Mater., 2014, 26, 56705677.

14 Y. Liu, J. Zhao, Z. Li, C. Mu, W. Ma, H. Hu, K. Jiang, H. Lin, H. Ade and H. Yan, Nat. Commun., 2014, 5, 5293.

15 L. Huo, X. Guo, S. Zhang, Y. Li and J. Hou, Macromolecules, 2011, 44, 4035-4037.

16 J.-S. Wu, S.-W. Cheng, Y.-J. Cheng and C.-S. Hsu, Chem. Soc. Rev., 2015, 44, 1113-1154.

17 J. Peet, J. Y. Kim, N. E. Coates, W. L. Ma, D. Moses, A. J. Heeger and G. C. Bazan, Nat. Mater., 2007, 6, 497-500.

18 Y. Zhang, J. Zou, C.-C. Cheuh, H.-L. Yip and A. K. Y. Jen, Macromolecules, 2012, 45, 5427-5435.

19 C.-Y. Chang, L. Zuo, H.-L. Yip, Y. Li, C.-Z. Li, C.-S. Hsu, Y.-J. Cheng, H. Chen and A. K. Y. Jen, Adv. Funct. Mater., 2013, 23, 5084-5090.

20 S. Albrecht, S. Janietz, W. Schindler, J. Frisch, J. Kurpiers, J. Kniepert, S. Inal, P. Pingel, K. Fostiropoulos, N. Koch and D. Neher, J. Am. Chem. Soc., 2012, 134, 14932-14944.

21 Y. Li, J. Zou, H.-L. Yip, C.-Z. Li, Y. Zhang, C.-C. Chueh, J. Intemann, Y. Xu, P.-W. Liang, Y. Chen and A. K. Y. Jen, Macromolecules, 2013, 46, 5497-5503.

22 C.-Y. Chang, L. Zuo, H.-L. Yip, C.-Z. Li, Y. Li, C.-S. Hsu, Y.-J. Cheng, H. Chen and A. K. Y. Jen, Adv. Energy Mater., 2014, 4, 1301645.

23 J. Min, Z.-G. Zhang, S. Zhang and Y. Li, Chem. Mater., 2012, 24, 3247-3254.

24 C. Gu, M. Xiao, X. Bao, L. Han, D. Zhu, N. Wang, S. Wen, W. Zhu and R. Yang, Polym. Chem., 2014, 5, 6551-6557.
25 J. Hou, H.-Y. Chen, S. Zhang, G. Li and Y. Yang, J. Am. Chem. Soc., 2008, 130, 16144-16145.

26 T. Y. Chu, J. Lu, S. Beaupre, Y. Zhang, J. R. Pouliot, S. Wakim, J. Zhou, M. Leclerc, Z. Li, J. Ding and Y. Tao, J. Am. Chem. Soc., 2011, 133, 4250-4253.

27 M. C. Scharber, M. Koppe, J. Gao, F. Cordella, M. A. Loi, P. Denk, M. Morana, H. J. Egelhaaf, K. Forberich, G. Dennler, R. Gaudiana, D. Waller, Z. Zhu, X. Shi and C. J. Brabec, Adv. Mater., 2010, 22, 367-370.

28 H. Y. Chen, J. Hou, A. E. Hayden, H. Yang, K. N. Houk and Y. Yang, Adv. Mater., 2010, 22, 371-375.

29 J.-S. Wu, Y.-J. Cheng, T.-Y. Lin, C.-Y. Chang, P.-I. Shih and C.-S. Hsu, Adv. Funct. Mater., 2012, 22, 1711-1722.

30 C. P. Chen and H. L. Hsu, Macromol. Rapid Commun., 2013, 34, 1623-1628.

31 S. Ko, E. T. Hoke, L. Pandey, S. Hong, R. Mondal, C. Risko, Y. Yi, R. Noriega, M. D. McGehee, J. L. Bredas, A. Salleo and Z. Bao, J. Am. Chem. Soc., 2012, 134, 5222-5232.

32 N. Wang, Z. Chen, W. Wei and Z. Jiang, J. Am. Chem. Soc., 2013, 135, 17060-17068.

33 C.-H. Chen, C.-H. Hsieh, M. Dubosc, Y.-J. Cheng and C.-S. Hsu, Macromolecules, 2010, 43, 697-708.

34 M. J. Frisch, G. W. Trucks, H. B. Schlegel, G. E. Scuseria, M. A. Robb, J. R. Cheeseman, G. Scalmani, V. Barone, B. Mennucci, G. A. Petersson, H. Nakatsuji, M. Caricato, X. Li, H. P. Hratchian, A. F. Izmaylov, J. Bloino, G. Zheng, J. L. Sonnenberg, M. Hada, M. Ehara, K. Toyota, R. Fukuda, J. Hasegawa, M. Ishida, T. Nakajima, Y. Honda, O. Kitao, H. Nakai, T. Vreven, J. A. Montgomery, J. E. Peralta, F. Ogliaro, M. Bearpark, J. J. Heyd, E. Brothers, K. N. Kudin, V. N. Staroverov, R. Kobayashi, J. Normand, K. Raghavachari, A. Rendell, J. C. Burant, S. S. Iyengar, J. Tomasi, M. Cossi, N. Rega, J. M. Millam, M. Klene, J. E. Knox, J. B. Cross, V. Bakken, C. Adamo, J. Jaramillo, R. Gomperts, R. E. Stratmann, O. Yazyev, A. J. Austin, R. Cammi, C. Pomelli, J. W. Ochterski, R. L. Martin, K. Morokuma, V. G. Zakrzewski, G. A. Voth, P. Salvador, J. J. Dannenberg, S. Dapprich, A. D. Daniels, Ö. Farkas, J. B. Foresman, J. V. Ortiz, J. Cioslowski and D. J. Fox, Gaussian 09, Revision A.1, Gaussian, Inc., Wallingford, CT, 2009.

35 T. L. Nguyen, H. Choi, S.-J. Ko, M. A. Uddin, B. Walker, S. Yum, J.-E. Jeong, M. H. Yun, T. J. Shin, S. Hwang, J. Y. Kim and H. Y. Woo, Energy Environ. Sci., 2014, 7, 30403051.

36 B. C. Schroeder, Z. Huang, R. S. Ashraf, J. Smith, P. D'Angelo, S. E. Watkins, T. D. Anthopoulos, J. R. Durrant and I. McCulloch, Adv. Funct. Mater., 2012, 22, 1663-1670.

37 S. Zhang, L. Ye, Q. Wang, Z. Li, X. Guo, L. Huo, H. Fan and J. Hou, J. Phys. Chem. C, 2013, 117, 9550-9557.

38 L. Dou, C.-C. Chen, K. Yoshimura, K. Ohya, W.-H. Chang, J. Gao, Y. Liu, E. Richard and Y. Yang, Macromolecules, 2013, 46, 3384-3390.

39 C. Cabanetos, A. El Labban, J. A. Bartelt, J. D. Douglas, W. R. Mateker, J. M. Frechet, M. D. McGehee and P. M. Beaujuge, J. Am. Chem. Soc., 2013, 135, 4656-4659. 
40 X. Wang, Y. Sun, S. Chen, X. Guo, M. Zhang, X. Li, Y. Li and H. Wang, Macromolecules, 2012, 45, 1208-1216.

41 Z. G. Zhang, J. Min, S. Zhang, J. Zhang, M. Zhang and Y. Li, Chem. Commun., 2011, 47, 9474-9476.

42 S. C. Price, A. C. Stuart, L. Yang, H. Zhou and W. You, J. Am. Chem. Soc., 2011, 133, 4625-4631.

43 H.-Y. Chen, J. Hou, S. Zhang, Y. Liang, G. Yang, Y. Yang, L. Yu, Y. Wu and G. Li, Nat. Photonics, 2009, 3, 649-653.

44 L. J. A. Koster, V. D. Mihailetchi and P. W. M. Blom, Appl. Phys. Lett., 2006, 88, 093511.

45 M. Zhang, X. Guo, W. Ma, S. Zhang, L. Huo, H. Ade and J. Hou, Adv. Mater., 2014, 26, 2089-2095.
46 H.-C. Chen, Y.-H. Chen, C.-C. Liu, Y.-C. Chien, S.-W. Chou and P.-T. Chou, Chem. Mater., 2012, 24, 4766-4772.

47 S. Liu, X. Bao, W. Li, K. Wu, G. Xie, R. Yang and C. Yang, Macromolecules, 2015, 48, 2948-2957.

48 G. Ren, E. Ahmed and S. A. Jenekhe, Adv. Energy Mater., 2011, 1, 946-953.

49 J. M. Lobez, T. L. Andrew, V. Bulović and T. M. Swager, ACS Nano, 2012, 6, 3044-3056.

50 X. Hu, C. Yi, M. Wang, C.-H. Hsu, S. Liu, K. Zhang, C. Zhong, F. Huang, X. Gong and Y. Cao, Adv. Energy Mater., 2014, 4, 14000378.

51 H. Zhou, L. Yang, A. C. Stuart, S. C. Price, S. Liu and W. You, Angew. Chem. Int. Ed., 2011, 50, 2995-2998. 